\title{
BMJ Open 10-year trends in statin utilization in Taiwan: a retrospective study using Taiwan's National Health Insurance Research Database
}

\author{
Hsing-Chun Hsieh, ${ }^{1,2}$ Jason C Hsu, ${ }^{1}$ Christine $Y \mathrm{Lu}^{3}$
}

To cite: Hsieh H-C, Hsu JC, Lu CY. 10-year trends in statin utilization in Taiwan: a retrospective study using Taiwan's National Health Insurance Research Database. BMJ Open 2017;7:e014150. doi:10.1136/ bmjopen-2016-014150

- Prepublication history and additional material are available. To view please visit the journal (http://dx.doi.org/ 10.1136/ bmjopen-2016-014150).

Received 7 September 2016 Revised 28 January 2017 Accepted 22 March 2017

\section{(a) CrossMark}

${ }^{1}$ School of Pharmacy and Institute of Clinical Pharmacy and Pharmaceutical Sciences, College of Medicine, National Cheng Kung University, Tainan, Taiwan

${ }^{2}$ Department of Pharmacy, Chi Mei Medical Center, Tainan, Taiwan

${ }^{3}$ Department of Population Medicine, Harvard Medical School and Harvard Pilgrim Health Care Institute, Boston, Massachusetts, USA

Correspondence to Dr Jason C Hsu; jasonhsuharvard@gmail.com

\section{ABSTRACT}

Objective Statins have been commonly used to treat patients with hypercholesterolaemia and to prevent cardiovascular disease (CVD) worldwide. This study examined trends in use of statins in Taiwan from 2002 to 2011.

Design This is a retrospective observational study focusing on the utilisation of statins.

Setting The monthly claims data for statins between 2002 and 2011 were retrieved from Taiwan's National Health Insurance Research Database.

Main outcome measures We calculated the yearly prescription rate per new user for each statin. Products were classified as high-intensity/moderate-intensity/lowintensity statins by type of statin and dosage. Users were also classified based on disease histories.

Results The number of statin users increased from 10299 ( 1.4\% of adults) in 2002 to 50687 ( 6.3\% of adults) in 2011. Atorvastatin was the most commonly used agent $(28.4 \%-36.7 \%)$ during the study period. After 2007, simvastatin ranked second with $21.7 \%$ market share, followed by rosuvastatin, a newer agent that exhibited a substantial growth in prescription rates $(3.4 \%$ in 2005 and $19.5 \%$ in 2011). In 2011, 94.0\% of new statin users used statin monotherapies, and $6.0 \%$ used combination therapies. Use of moderate-intensity statins increased from $49.0 \%$ in 2002 to $71.0 \%$ in 2011, while high-intensity statins remained low. Patients with history of coronary events or cerebrovascular events were more likely to be prescribed higher intensity statins compared with those without. Prescribing of higher intensity statins was not greater among people with diabetes compared with those without during 2007-2011. Selection of statins did not differ between people with versus without history of myopathy or liver injury.

Conclusion Atorvastatin was the most commonly used statin in Taiwan during 2002-2011. While patients with history of CVD were more likely to be prescribed higher intensity statins compared with those without, this difference was not found comparing those with and without diabetes.

\section{INTRODUCTION}

Coronary heart disease accounts for approximately one-third of global deaths in recent years. ${ }^{1} \quad$ Similarly, cardiovascular diseases

\section{Strengths and limitations of this study}

- This is the first study to investigate 2002-2011 trends in prescribing patterns of statins among new statin users in Taiwan.

- Data were retrieved from Taiwan's National Health Insurance Research Database with nearly 99\% of the Taiwanese population (around 23 million residents) enrolled and $97 \%$ of hospitals and clinics throughout the country.

- While patients with history of cardiovascular disease were more likely to be prescribed higher intensity statins compared with those without, this difference was not found comparing those with and without diabetes. Appropriateness of statin use among diabetes needs further investigation.

(CVD) are leading causes of death in Taiwan. $^{2}$ Low-density lipoprotein cholesterol (LDL-C) has been identified as one of the major modifiable risk factors of CVD. ${ }^{3-6}$ Fundamental lifestyle changes and several medications have been recommended to control blood cholesterol. Among all medicines, 3-hydroxy-3-methylglutaryl-coenzyme A reductase inhibitors, or statins, are a major drug class given their efficacy in reducing LDL-C. $^{7-9}$ On average, administration of statins helps to lower LDL-C by $20 \%$ to $60 \% .{ }^{6}{ }^{10-12}$ In addition to lowering cholesterol, statins are shown to decrease risk of coronary events by $18 \%$, myocardial infarction by $24 \%$ and heart failure by $35 \%{ }^{13}$

Statins are recommended by major clinical guidelines as the drug of choice for reduction of blood lipids to prevent CVD globally. ${ }^{7-9} \mathrm{In}$ the USA, the 2013 'American College of Cardiology/American Heart Association (ACC/ AHA)' Guideline ${ }^{7}$ recommends that patients with CVD history or with CVD risk factors, such as high LDL-C and diabetes, receive moderate-to-high-intensity statins. ${ }^{7} \quad$ The European Society of Cardiology (ESC) and 
UK's National Institute for Health and Care Excellence guidelines suggest prescribing statins with the highest recommended dose in order to reach target cholesterol level. ${ }^{89}$ In Taiwan, prescribing of statins generally follows drug coverage requirements under the National Health Insurance (NHI), which recommends the use of statins in patients with CVD risk factors or with high cholesterol level. ${ }^{14}$ It is reasonable for patients to be prescribed with a statin plus another lipid-lowering agent if triglyceride level is also high.

Statins have been the most commonly prescribed drugs in the world in recent decades; their global market sales reached around $\$ 28.5$ billion in $2014 .{ }^{1516}$ Previous studies from the USA and Europe showed substantial increases in statin users, prescription rates and prescribed daily doses of statins over time. ${ }^{17-19}$ Likewise in Taiwan statin users grew from 190000 in 2000 to nearly 600000 in 2004, and drug expenditures and prescription doses escalated over $200 \%$ and $400 \%$, respectively. ${ }^{20}{ }^{21}$ Based on the updated clinical guidelines and related evidence, use of the more intense statin therapy for secondary prevention and initiation of statins for primary prevention among patients who are at a higher risk of CVD has increased. ${ }^{722}$

While statins have been the mainstay of cholesterol control and heart attack and stroke prevention for the past 20 years, the treatment paradigm may change with the availability of new drugs that target an enzyme called PCSK9 (PCSK9 inhibitors) in 2015. ${ }^{23}$ However, little is known about recent statin use in Taiwan. ${ }^{24}$ The aims of this study were to examine the prescribing patterns of statins over the last decade and to investigate the association between patients' medical history and drug selection of statin. Our study results can be used to improve rational use of statins in light of clinical recommendations. At present, PCSK9 inhibitors are not yet reimbursed by Taiwan's National Health Insurance (NHI). Our findings also provide baseline trends that can be used to examine how new PCSK9 inhibitors, once become available under the NHI, impact the market of cholesterol medications.

\section{METHODS}

This study used claims data from the 2010 Longitudinal Health Insurance Database (LHID2010) derived from Taiwan's National Health Insurance Research Database (NHIRD), which compiles data of over $99 \%$ of people (around 23 million residents) in Taiwan. ${ }^{25}$ LHID2010 contains all the original claims data of 1 million beneficiaries randomly sampled in year 2010 from the NHIRD. LHID2010 data are overall representative of all beneficiaries as no significant differences were found in the distributions of age, gender and average premium rate between individuals in the LHID2010 and the original NHIRD data sets. ${ }^{26}$ The data set provides information on demographic characteristics, diseases diagnosis, treatment and related medical expenditures, and orders of ambulatory and inpatient care.
New statin users in each year during 2002-2011 were included and formed the study population of each year. New statin users were defined as those who had not taken any statin in the previous years prior to the index date. The index date of every patient in each study year was defined as the date of the first statin prescription in the year. For patients in every study year, only the first prescription that contained any statins was examined in this study. We used the Anatomical Therapeutic Chemical (ATC) $\operatorname{codes}^{27}$ to identify patients who were prescribed any statins, including atorvastatin, fluvastatin, lovastatin, pravastatin, rosuvastatin and simvastatin. Monotherapy was defined as only one statin prescription on the index date, while combination therapy was defined by prescriptions for a statin plus other lipid-lowering drugs (such as fibrates) on the index date.

The main measure was yearly prescription rate of each statin among new statin users. Yearly prescription rate of a specific statin agent was calculated by the number of patients prescribed with the specific statin agent divided by the total number of new statin users in the year. We also calculated the yearly prescription rates of monotherapy/combined statin therapy and of different levels of intensity.

Statins were grouped into three levels of intensity according to their ability to lower LDL-C based on the 2013 ACC/AHA Guideline on the Treatment of Blood Cholesterol $^{7}$ and Rosenson et $a l^{28}$ : (1) high-intensity statins: atorvastatin $\geqq 40 \mathrm{mg} /$ day, rosuvastatin $\geqq 20 \mathrm{mg} /$ day and simvastatin $\geqq 80 \mathrm{mg} /$ day; (2) moderate-intensity statins: $10 \mathrm{mg} /$ day $\leqq$ atorvastatin $<40 \mathrm{mg} /$ day, $5 \mathrm{mg} /$ day $\leqq$ rosuvastatin $<20 \mathrm{mg} /$ day, $20 \mathrm{mg} /$ day $\leqq$ simvastatin $<80 \mathrm{mg} /$ day, pravastatin $\geqq 40 \mathrm{mg} /$ day, lovastatin $\geqq 40 \mathrm{mg}$ / day and fluvastatin $\geqq 80 \mathrm{mg} /$ day; and (3) low-intensity statins: atorvastatin $<10 \mathrm{mg} /$ day, rosuvastatin $<5 \mathrm{mg}$ /day, simvastatin $<20 \mathrm{mg} /$ day, pravastatin $<40 \mathrm{mg} /$ day, lovastatin $<40 \mathrm{mg} /$ day and fluvastatin $<80 \mathrm{mg} /$ day. Daily dose can be calculated from the information of what statin has been prescribed, its dosage form, frequency and number of pills within a certain period.

All new statin users were also classified based on whether they have disease histories of interest (including coronary events, cerebrovascular events, myopathy, liver injury and diabetes) or not. Disease histories were identified by the International Classification of Diseases, 9th edition diagnosis codes for major coronary artery disease (410, 411), major cerebrovascular $(430,431,433-436)$, diabetes (250), ${ }^{29}$ myopathy $(792.1,359.4,359.8,359.9)$ and liver injury $(155.0,155.1,155.2,197.7,230.8,570$, $571.1,572.2,572.4,572.8,573.3,573.8,573.9,574.0,574.1$, $574.9,646.7) .{ }^{30}$ The first three diagnoses relate to use of statin for CVD prevention and the latter two diagnoses related to the potential adverse effects of statins. We anticipate a higher percentage use of higher intensity statins among patients with CVD or diabetes. Myopathy ${ }^{31}{ }^{32}$ and liver toxicity ${ }^{32} 33$ (increasing the enzymes aspartate transaminase and alanine transaminase) are two of the main dose-dependent side effects associated with statin use. ${ }^{3435}$ 
Therefore, it was anticipated that a higher percentage of patients with a history of these diseases would use low-intensity statins. Individuals were defined as having a history of the following diseases if they have a diagnosis within certain years prior to the given year: coronary event (3 years), cerebrovascular event ( 5 years), diabetes ( 1 year), myopathy ( 3 years) and liver injury (3 years). ${ }^{30} 36-38$

This study applied descriptive statistics to report the prescription rates of each statin and used $\chi^{2}$ test to investigate the associations between patients' disease history and statin drug selection. All analyses were carried out with SAS V.9.3 software and Excel 2013.

\section{RESULTS}

In 2002, 10299 ( 1.4\% of adults aged 18 and over) statin users were identified among the 1 million cohort from LHID2010 dataset (table 1). Among statin users, more than half $(\mathrm{n}=5956 ; 57.8 \%)$ were new users. Statins users grew from 10299 ( 1.4\% of adults) in 2002 to 50687 ( $6.3 \%$ of adults) in 2011 , while the proportion of new statin users declined from $57.8 \%$ to $35.0 \%$. More women used statins than men $(52.3 \%$ vs $47.7 \%$ in 2011$)$. The average age of new statin users remained steady (58-60 years old) during the study period. Three quarters of new statin users were diagnosed with dyslipidemia. Hypertension accounted for the highest proportion of comorbidities $(60.9 \%$ in 2011$)$, followed by diabetes (35.3\% in 2011); their rates remained steady during the study period. On the contrary, the proportions of other comorbidities, including ischaemic heart disease and chronic liver diseases, slightly declined over time.

Table 2 presents the statin choices among new statin users. Atorvastatin was the most commonly prescribed statin among new statin users throughout the study (33.8\% in 2002 and $35.8 \%$ in 2011). Lovastatin had the second highest prescription rates from $24.7 \%$ in 2002 to $24.2 \%$ in 2006, but it declined after 2007 to $5.8 \%$ in 2011. On the other hand, simvastatin became the second commonly used statin since 2007 (21.7\%), and its prescription rate peaked in 2009 (27.1\%). Rosuvastatin entered the market in 2005, and its prescription rate rapidly increased to $19.5 \%$ in 2011. Prescription rates of other statins remained relatively low. Figure 1 shows the prescribing trends of statins over time.

During the study period, almost all patients were prescribed with a single statin when they first started (98.6\% in 2002 and $94.0 \%$ in 2011). Only $1.4 \%$ of patients were prescribed with combination therapy in 2002, with fibrates accounting for $83.3 \%$ of the combination therapies. Use of combination therapy increased to $6.0 \%$ in 2011, with ezetimibe accounting for $66.2 \%$ of combined lipid-lowering drugs.

In 2002, prescription rates of low-intensity and moderate-intensity statins were similar $(51.0 \%$ and $49.0 \%)$. However, prescription rates of moderate-intensity statins gradually increased to $71.0 \%$ in 2011, while prescription rates of low-intensity statins gradually decreased to $27.3 \%$ in 2011. In comparison, use of high-intensity statins remained low (under 2.1\%) during the study period (figure 2).

Table 3 and figure 3 show the prescription rates of statins among new statin users with/without history of specific diseases. Compared with those without CVD, higher percentages of people with history of coronary events or cerebrovascular events were prescribed atorvastatin $(51.4 \%$ vs $35.6 \%$ and $42.7 \%$ vs $35.4 \%$, respectively, in 2011$)$ or rosuvastatin $(32.5 \%$ vs $19.3 \%$ and $27.5 \%$ vs $19.1 \%$, respectively, in 2011). In patients with myopathy or liver injury history, prescription rates of different statins did not vary greatly through the study period compared with those without history of the diseases. Similarly, prescription rates of different statins did not vary greatly between people with and without diabetes.

Table 4 indicates the findings of the associations between certain disease history and prescription of highor moderate-intensity statins. Patients with CVD history were more likely to be prescribed moderate-intensity or high-intensity statins (OR ranged from 1.52 to 2.83 during the study period, $\mathrm{p}<0.05)$. Similar results were found in patients with cerebrovascular events history compared with those without (OR ranged from 1.17 to 1.88 during 2006-2011, $\mathrm{p}<0.05)$. However, patients with diabetes history were less likely to be prescribed moderate-intensity or high-intensity statins compared with patients without diabetes history (OR ranged from 0.83 to 0.90 during 2007-2011, $\mathrm{p}<0.05$ ). No substantial differences in prescribing patterns of statins were observed throughout the study period in groups with versus without history of myopathy or liver injury (table 4 ).

\section{DISCUSSION}

This longitudinal study of a national cohort found that more than half statin users were initiated on a single statin, with atorvastatin being the most commonly prescribed statin over the last decade in Taiwan. Use of moderate-intensity statins increased by $22.0 \%$ between 2002 and 2011 , while use of high-intensity statins remained low. Lastly, patients with history of coronary events or cerebrovascular events were more likely to be prescribed higher intensity statins compared with those without. Prescribing of higher intensity statins was not greater among people with diabetes compared with those without during 20072011. This difference was also not seen in people with versus without history of myopathy or liver injury.

From 2002 to 2011, initiation of statins increased over time, similar to studies from other countries. ${ }^{18} 39-41$ Initiation of statins in Taiwan has grown from $0.6 \%$ in 2002 to $1.8 \%$ in 2011. Our findings are similar to studies from other countries that found similar utilisation rates and increasing trend over time. For instance, a study used data of Italian local pharmacies and demonstrated incidence of statin exposure growing from $0.36 \%$ in 1994 to $0.74 \%$ in $2003{ }^{42}$ Another study, which was also conducted in Italy, exhibited yearly incidence of statin 


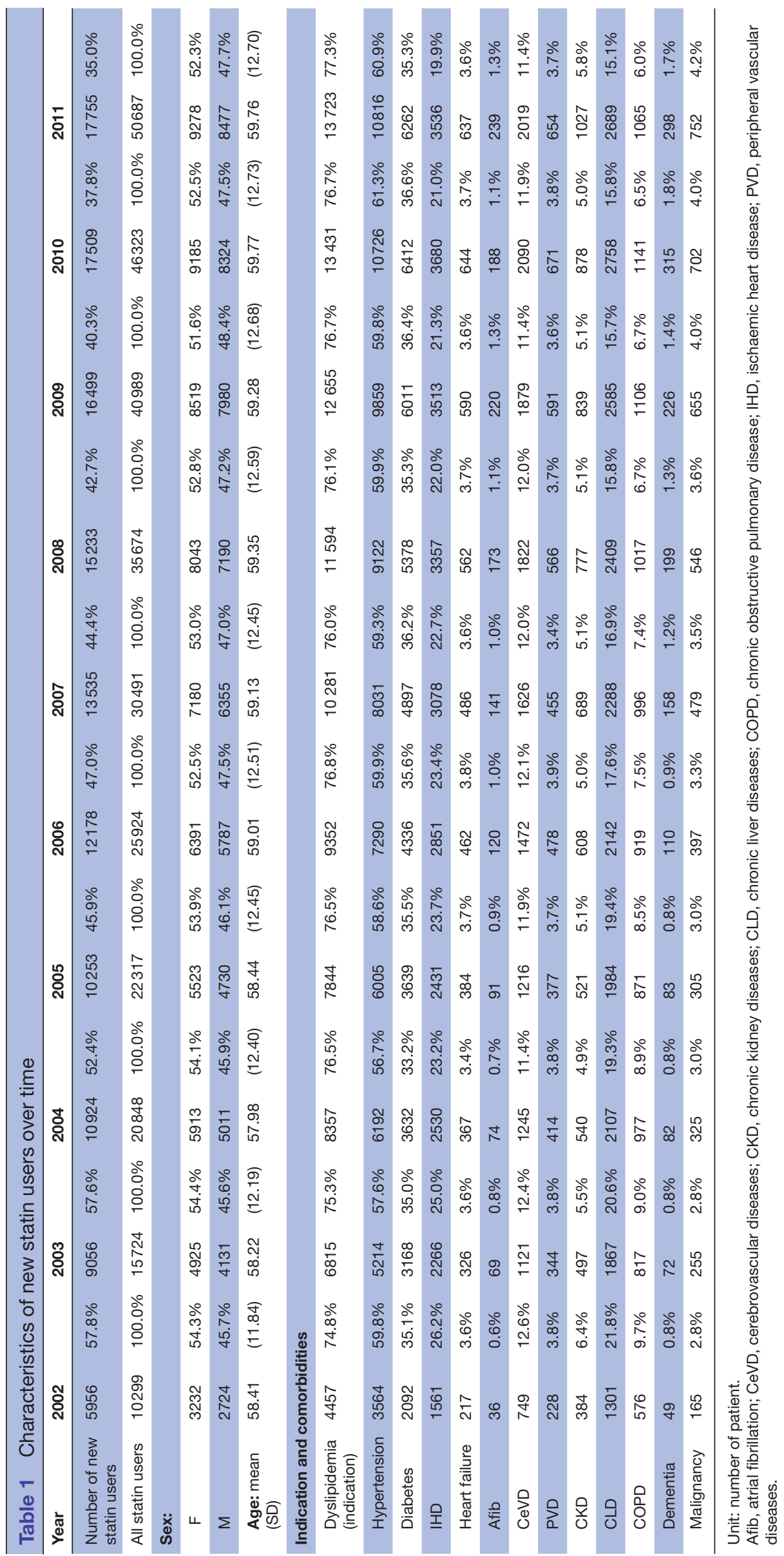


மी

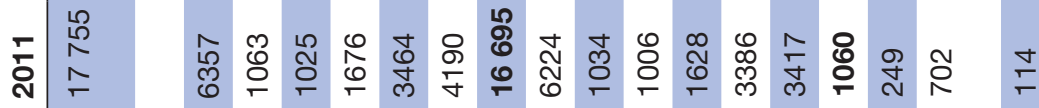

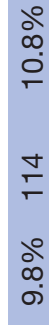

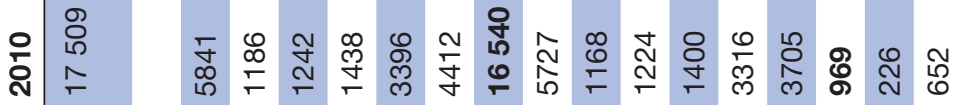

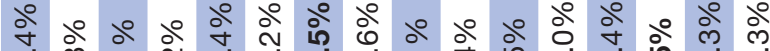
ल

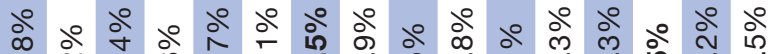

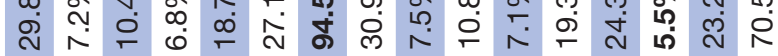

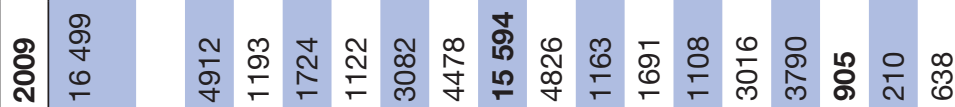

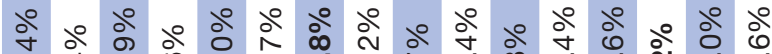

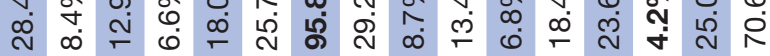

怘

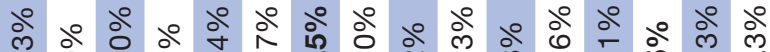
崩

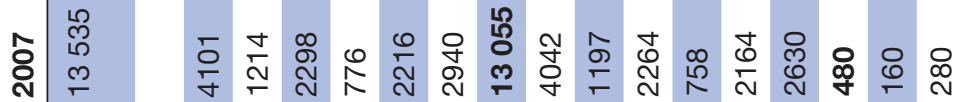
守

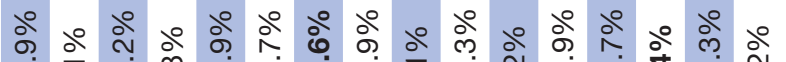
高 लं চं

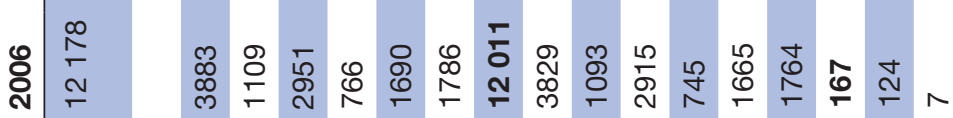

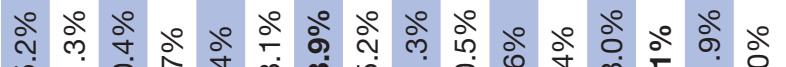
ம்

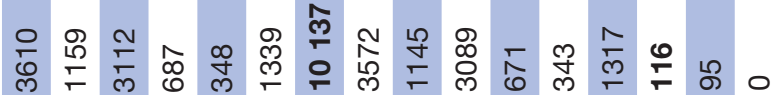

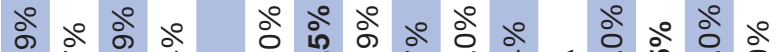
लि

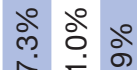

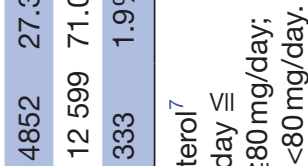

疋 $\simeq$ ल्ల

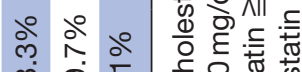

ஸ

+ ठ 冫

落

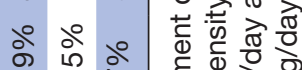

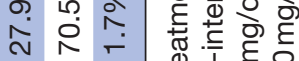

๙

Oे

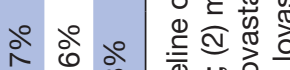

演市

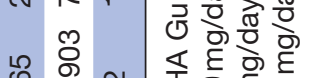

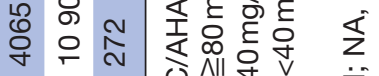

ले ॰

वें

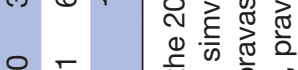

웋

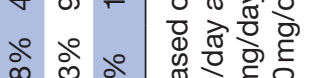

ن

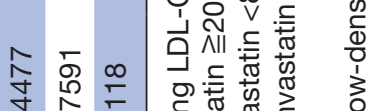

১0 ১0

守 h⿱宀 犬㔾

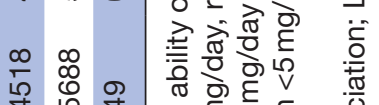

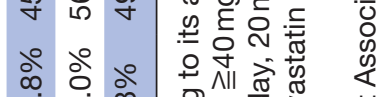

ஸे में

ㄴ

官

১ீ ১o

守

荈

寸

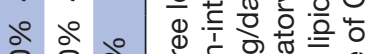

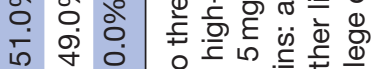

每

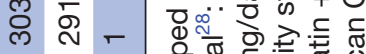

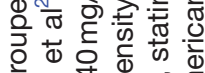

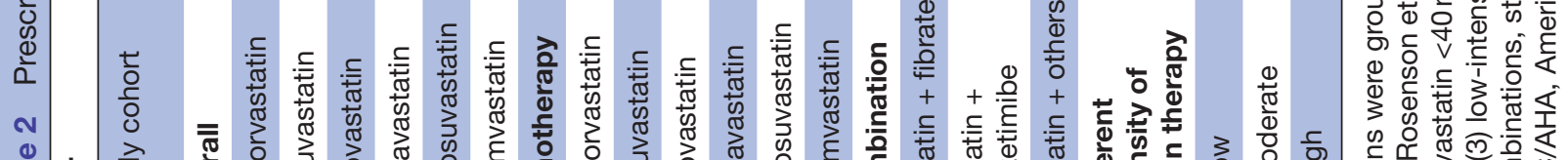

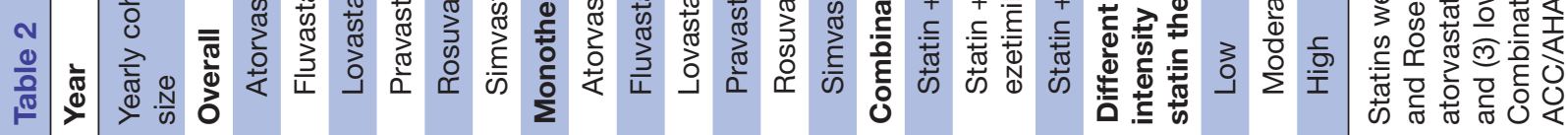

$\stackrel{\text { m }}{\gtrless}$

용

离

듬

$\frac{\bar{c}}{\bar{D}}$

ถัต

o

$\vec{\omega}$

음.

응

กิ

के

강

운

$\exists$

$\stackrel{2}{2}$

공

ํㅏㅇ

о

음

흑

릉

혹

要

음

ญิ

○

을.

กั

N

ए)

잉

뭉

욤

2

产 


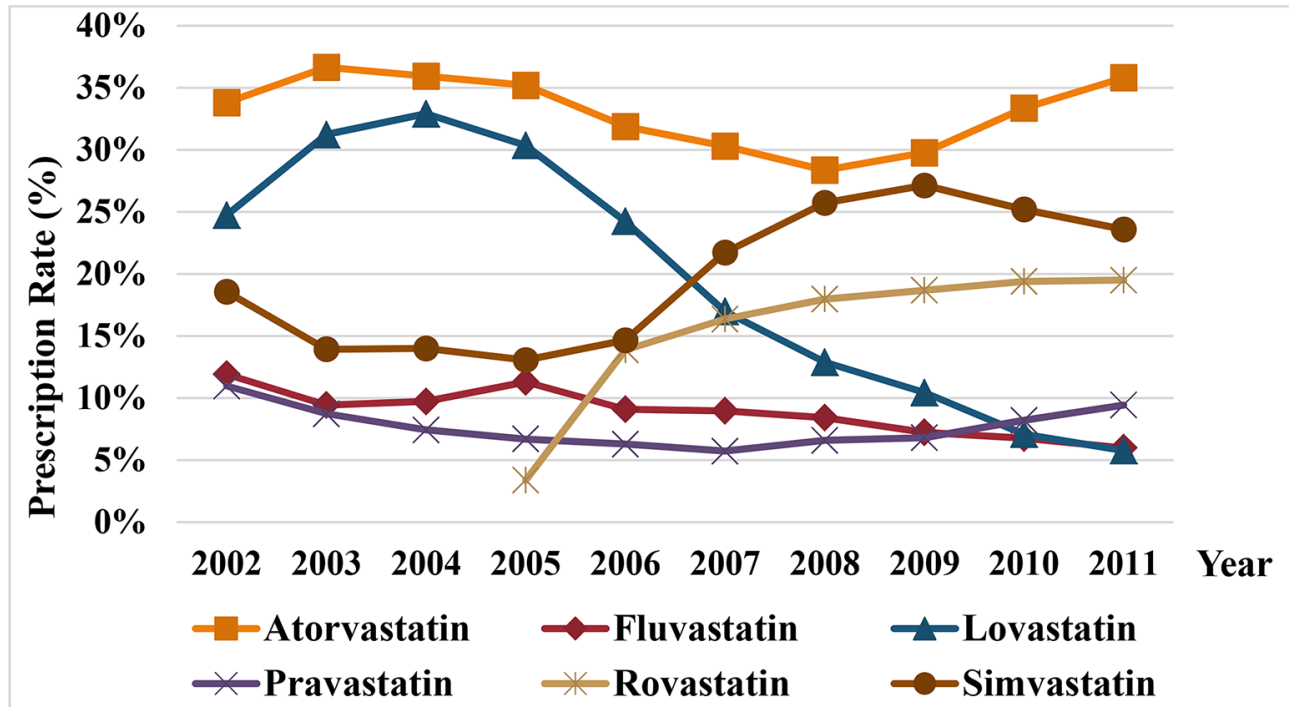

Figure 1 Prescribing rates of statins among new statin users from 2002 to 2011. All values were calculated in patient number. Yearly prescription rate $=$ number of patients prescribed with the specific statin agent / total number of new statin users in the year.

use increasing from 13.3/1000 inhabitants in 2005 to 19.5/1000 inhabitants in 2010 among people aged 15 and over. ${ }^{39} \mathrm{~A}$ study by Svensson et al aligned with the previous results showing annual rates of new statin use ranging from 14 to $20 / 1000$ person-years. ${ }^{40}$

Our study found that atorvastatin had the highest prescription rate in Taiwan throughout the entire study. It was first introduced into Taiwan's market in 2000 and its market share surged to surpass other agents of the same drug class since the first study year. ${ }^{21}$ In other countries, atorvastatin has also been one of the most commonly used statins. ${ }^{39} 4043$ The popularity of atorvastatin might be attributed to favourable research results suggesting its clinical benefits in preventing major coronary events ${ }^{44}$ as well as marketing strategies of the pharmaceutical company. ${ }^{45}$ When examining trends of different statins, it was noted that trends of atorvastatin and simvastatin exhibited opposite directions (figure 1). Since both statins were moderate-to-high potency agents, their similar potency may be a reason for the substitution observed. ${ }^{1246}$

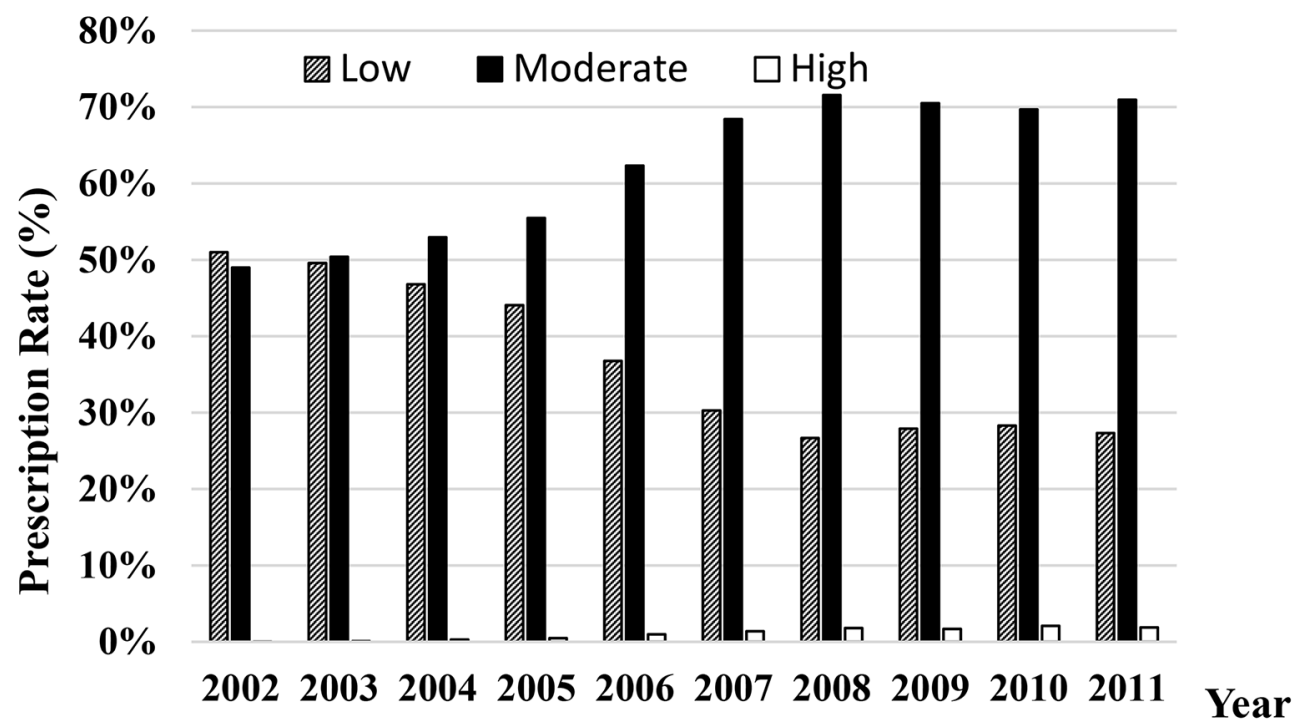

Figure 2 Prescribing rates of statins by intensity. All values were calculated in patient number. Yearly prescription rate = number of patients prescribed with the specific statin agent / total number of new statin users in the year. Statins were grouped into three levels of intensity according to their ability to lower LDL-C based on the 2013 ACC/AHA Guideline on the Treatment of Blood Cholesterol ${ }^{7}$ and Rosenson et $\mathrm{al}^{28}$ : (1) high-intensity statins: atorvastatin $\geqq 40 \mathrm{mg} /$ day, rosuvastatin $\geqq 20 \mathrm{mg} /$ day and simvastatin $\geqq 80 \mathrm{mg} /$ day; (2) moderate-intensity statins: $10 \mathrm{mg} /$ day $\leqq$ atorvastatin $<40 \mathrm{mg} /$ day, $5 \mathrm{mg} /$ day $\leqq$ rosuvastatin $<20 \mathrm{mg} /$ day, $20 \mathrm{mg} /$ day $\leqq$ simvastatin $<80 \mathrm{mg} /$ day, pravastatin $\geqq 40 \mathrm{mg} /$ day, lovastatin $\geqq 40 \mathrm{mg} /$ day and fluvastatin $\geqq 80 \mathrm{mg} /$ day; and (3) low-intensity statins: atorvastatin $<10 \mathrm{mg} /$ day, rosuvastatin $<5 \mathrm{mg} /$ day, simvastatin $<20 \mathrm{mg} /$ day, pravastatin $<40 \mathrm{mg} /$ day, lovastatin $<40 \mathrm{mg} /$ day and fluvastatin $<80 \mathrm{mg} /$ day. ACC/AHA, American College of Cardiology/American Heart Association; LDL-C, low-density lipoprotein cholesterol. 
$\frac{\bar{\alpha}}{2}$

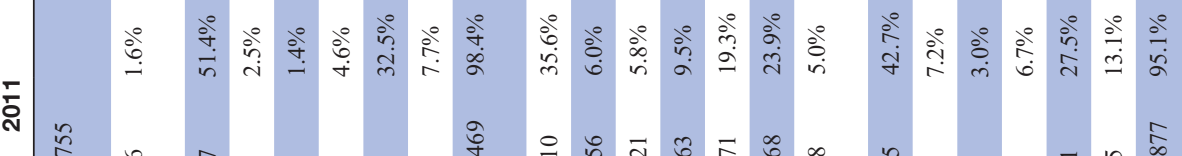

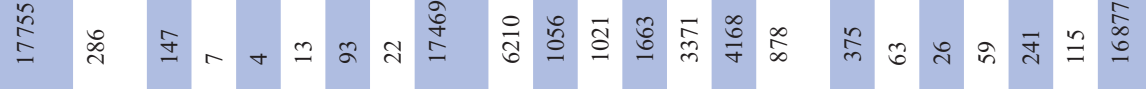

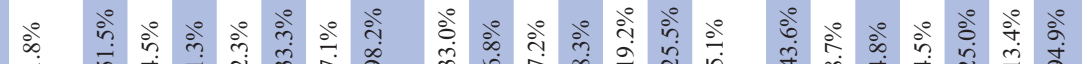

울

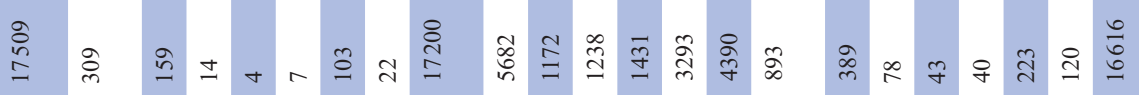

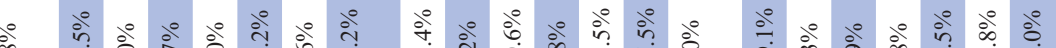

:

ले के

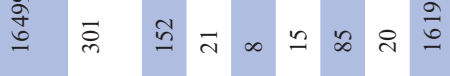

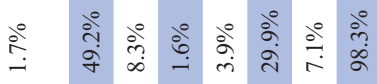

:

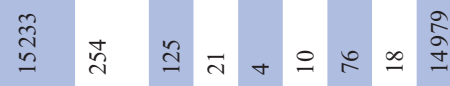

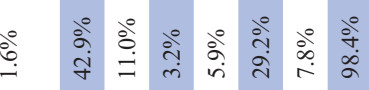

ฉิ

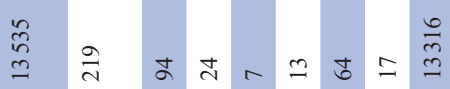

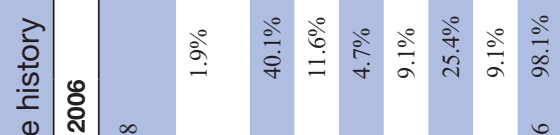

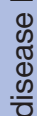

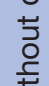

$\sum_{\substack{3 \\ 3}}^{3}$

रो

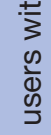

离

๙ิ

竞

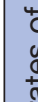

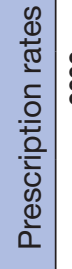

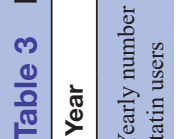

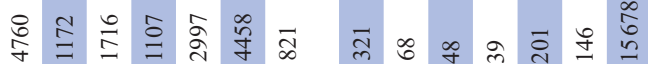

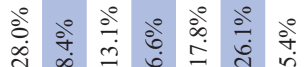

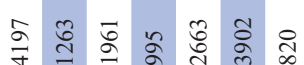

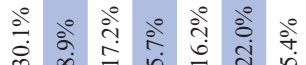

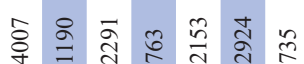

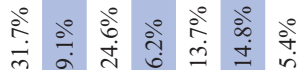

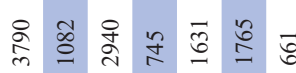

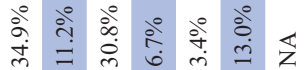

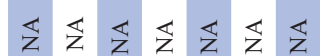

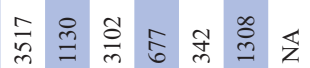

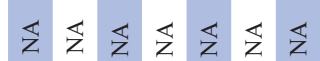

仓ें

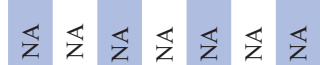

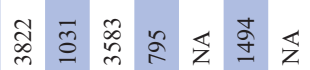

苂苂苂苂苂苂苂

苂苂苂苂苂苂

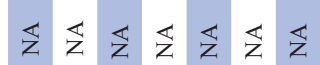

$\overleftrightarrow{z} \overleftrightarrow{z} \overleftrightarrow{z} \overleftrightarrow{z} \overleftrightarrow{z}$

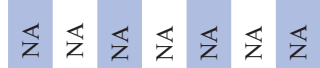

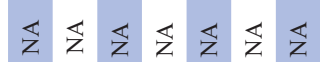

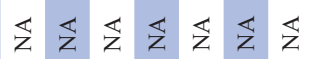

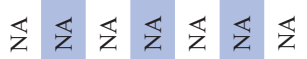

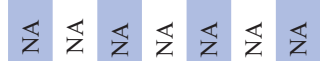

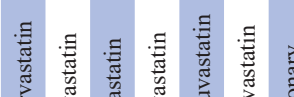

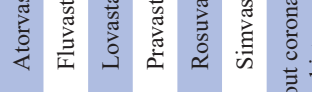

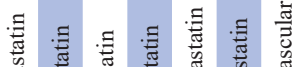

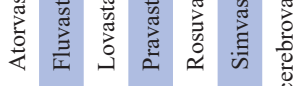

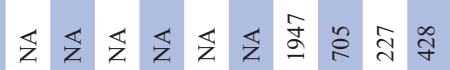

穴

ळ \&

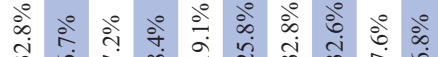

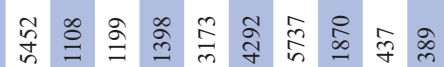

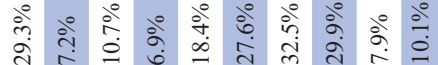

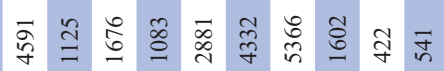

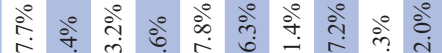

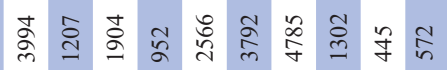

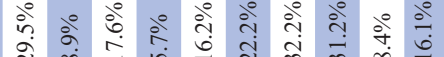

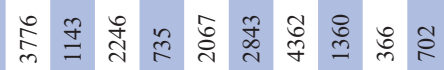

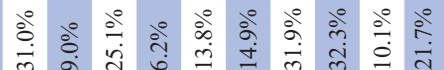

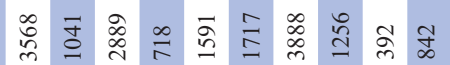

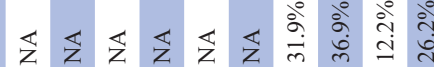

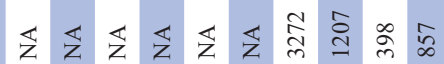

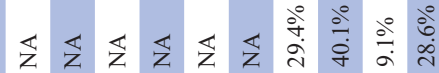

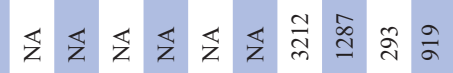

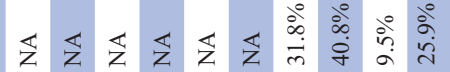

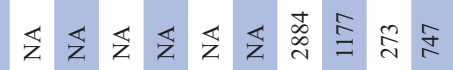

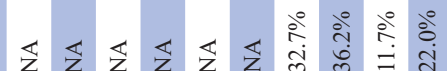

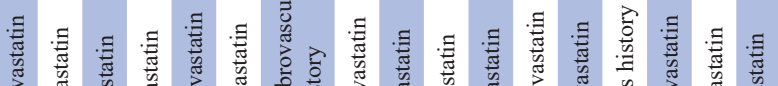

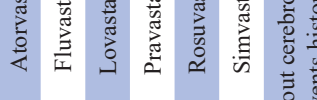

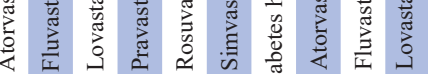
要 
స్⿱亠乂

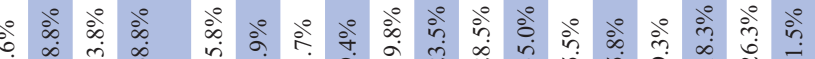

ह

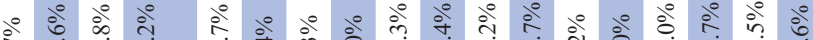

운

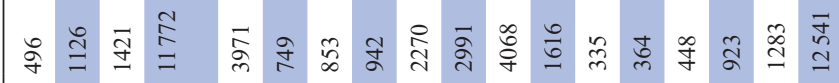

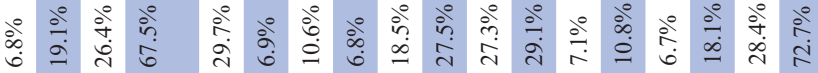

:ัे

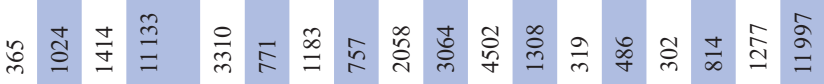

ڤे

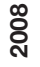

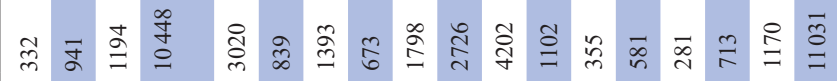

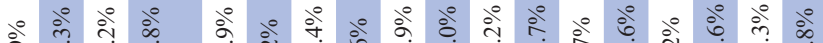

ڤิ

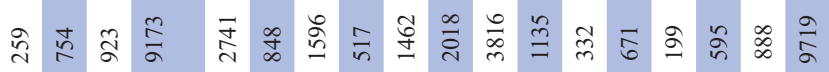

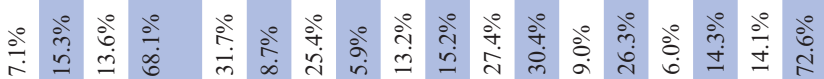

\&ั.

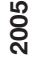

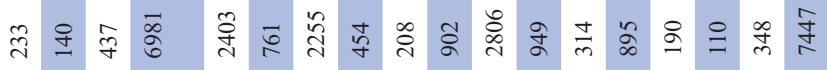

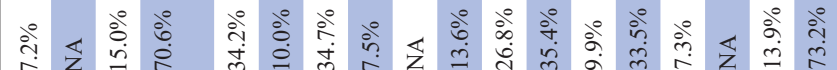

高

ถั้

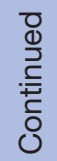

ชั่

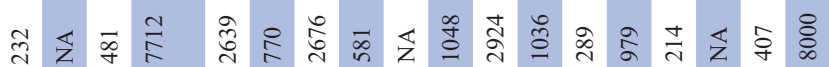

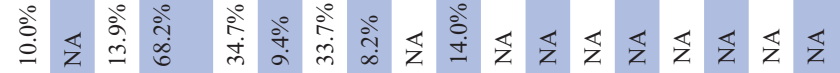

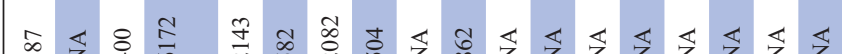

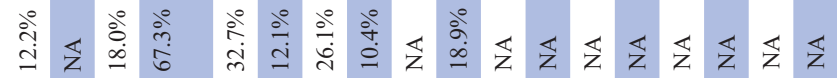

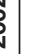

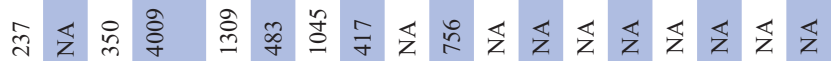

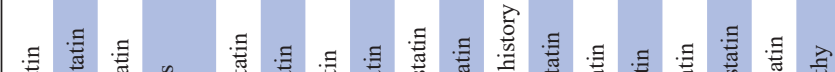

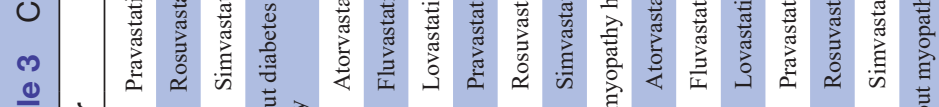

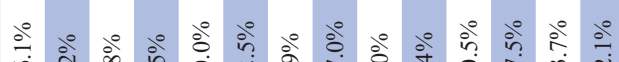

仓ั

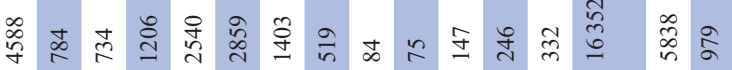

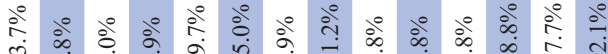

in

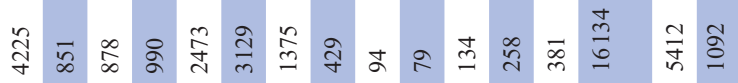

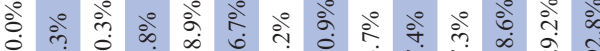

ํำ

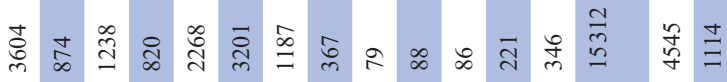

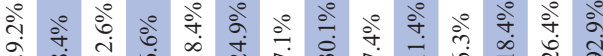

๙ें

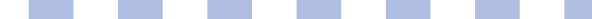

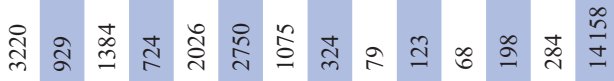

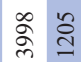

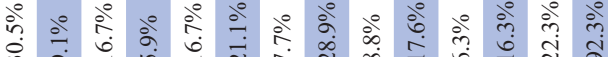
ఫें

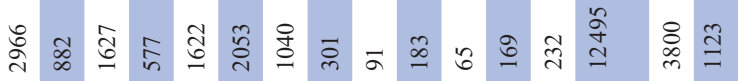

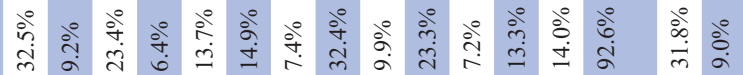
t.

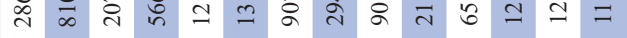

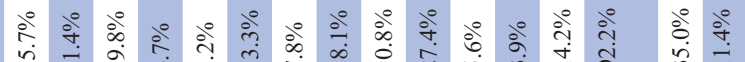
ప্ণ

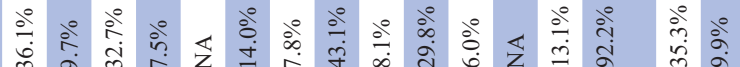

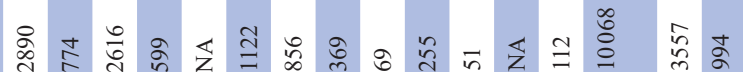

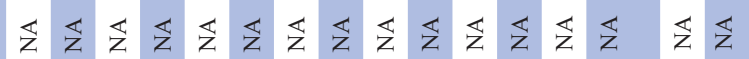

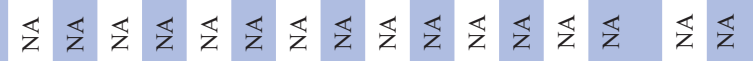

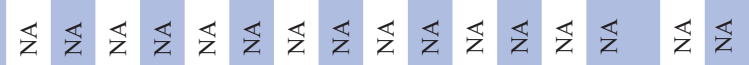

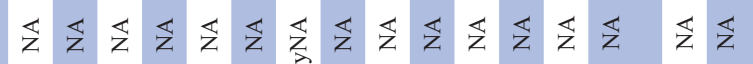

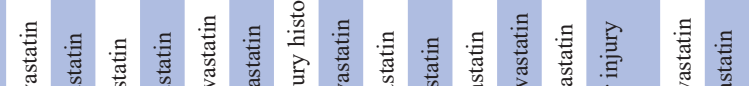

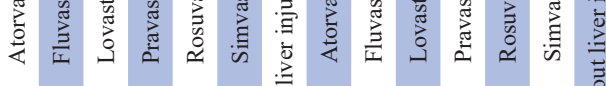




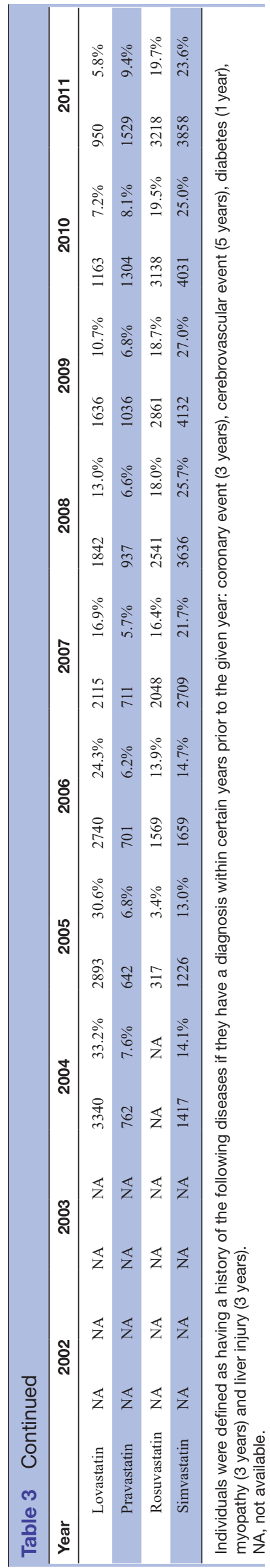

Another high-potency statin-rosuvastatin-manifested an increase in prescription rates since its market entry at 2005 . The growth in use of atorvastatin, simvastatin (+/ezetimibe) and rosuvastatin suggests treatment trending towards use of high-potency or moderate-to-high-intensity statin therapy, which is aligned with major clinical guidelines. $^{7-9}$

The majority of statin regimen stayed within the moderate-intensity range rather than high-intensity therapy, which remained less than 5\% during the study period. In a study from USA, relatively lower percentage (approximately $20 \%$ of total statin use) of high-intensity statin therapy was reported among adults $\geqq 40$ years old during 2002-2013. ${ }^{47}$ In comparison, our study reveals substantially low use of high-intensity statin, suggesting that there is room for improving rational use of statins in Taiwan.

Few statin users initiated with combination therapy overall. Use of combined lipid-lowering agents shifted from fibrates $(83.3 \%$ in 2002$)$ to ezetimibe $(66.2 \%$ in 2011). Ezetimibe entered Taiwan's market under the National Insurance coverage in 2006 as a combination drug with simvastatin (tradename Vytorin). High uptake of ezetimibe products might be associated with the evidence that ezetimibe plus simvastatin is more effective in lowering LDL-C than simvastatin alone. ${ }^{48} 49$

Our findings demonstrated an association between having a history of CVD and high-intensity or moderate-intensity statin use. Similarly other studies have reported that patients with CVD histories were prescribed statins with higher intensity or doses. ${ }^{19}{ }^{50}$ Use of statins among these individuals might have been appropriately influenced by clinical guidelines and related evidence suggesting more intensive statin therapy reduces cardiovascular events in patients with prior CVD. ${ }^{22}$ While diabetes has been viewed as a coronary risk equivalent, ${ }^{51}$ we did not find greater use of higher intensity statins among those with diabetes. A possible explanation might include the accumulating evidence suggesting the association between statin use and increasing risk of diabetes ${ }^{5253}$ and the deterioration of glucose control in patients receiving higher intensity statin regimens. ${ }^{54}$ Appropriateness of statin use among diabetes needs further investigation. Interestingly, we did not find different patterns of statin use between those with and without history of myopathy or liver diseases. This finding suggests that these side effects might not be of a primary concern when prescribing statin therapy in Taiwan.

This study contributes to the literature by examining the prescribing patterns of statins during 2002-2011 in Taiwan, including statin choices among patients with certain medical histories. Despite these strengths, it does have limitations. First, our analysis was based on claims data, which do not contain patients' biochemical test data (such as level of LDL-C), so we could not assess prescription patterns by disease severity. Second, this study only examined statin use among new users; we did not assess switches between statins. Further research is needed to 
a. With coronary events history

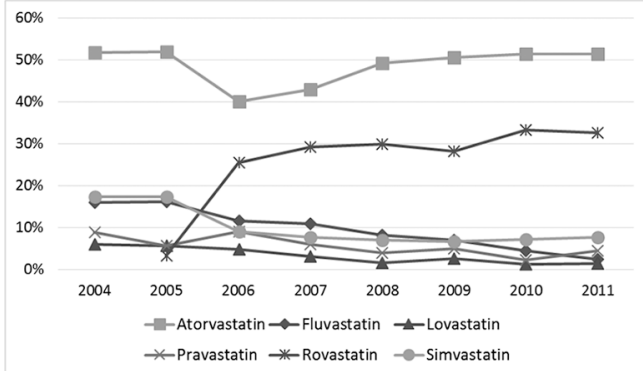

\section{With cerebrovascular events history}

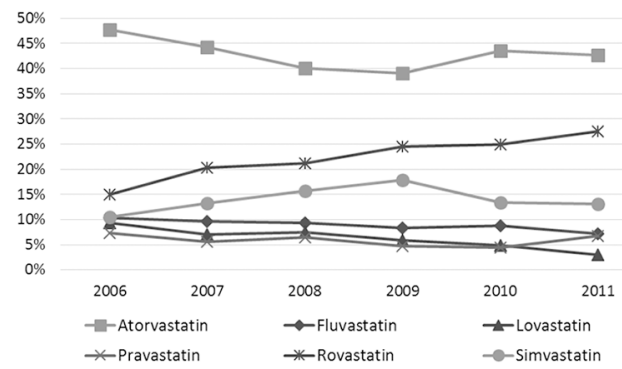

e. With diabetes history

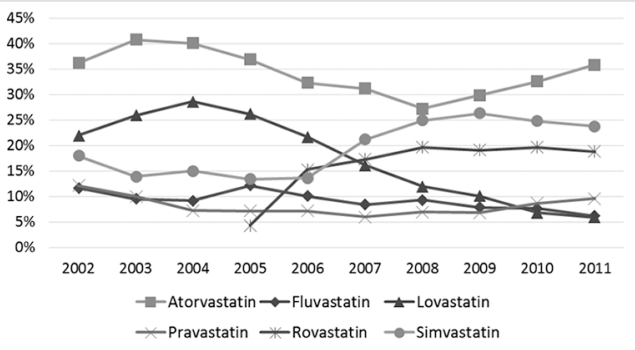

\section{g. Nith myopathy history}

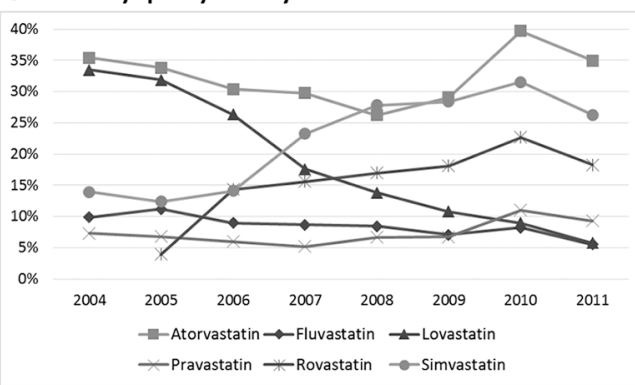

i. With liver injury history

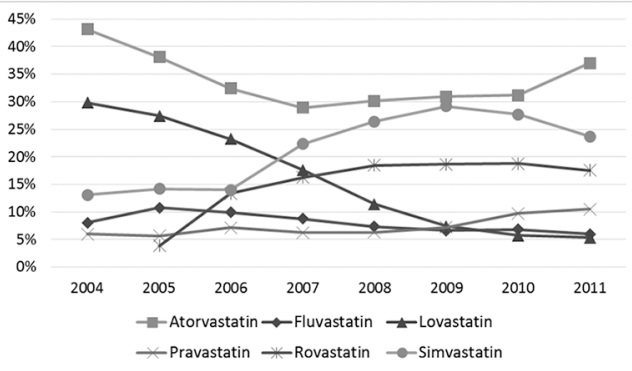

\section{b. Without coronary events history}

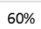

$50 \%$

$40 \%$

$30 \%$

$20 \%$

$10 \%$

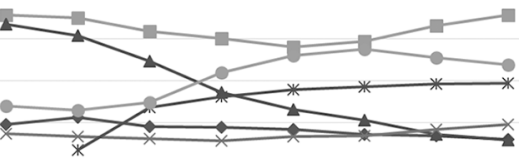

$\begin{array}{llllllll}2004 & 2005 & 2006 & 2007 & 2008 & 2009 & 2010 & 2011\end{array}$

$\rightarrow$-Atorvastatin $\rightarrow$ Fluvastatin $\rightarrow$-Lovastatin

* Pravastatin $\#$ Rovastatin $\rightarrow$-Simvastatin

\section{d. Without cerebrovascular events history}

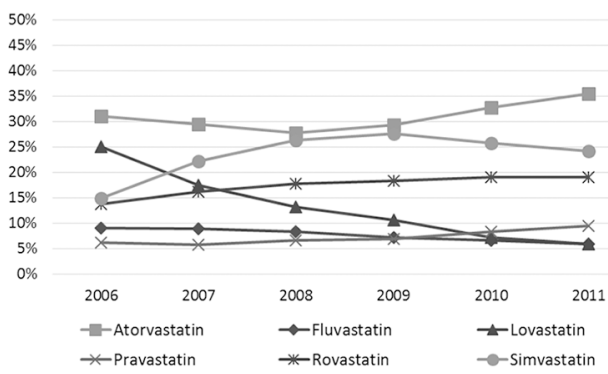

f. Without diabetes history

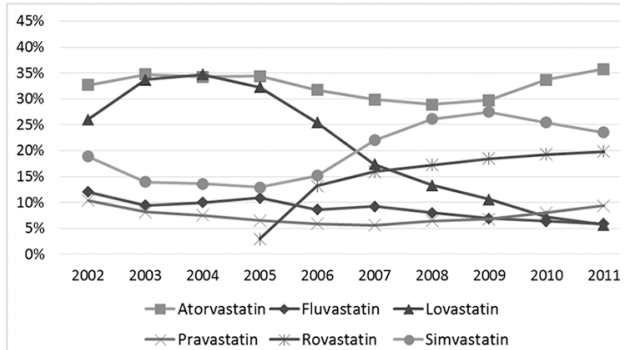

h. Without myopathy events history

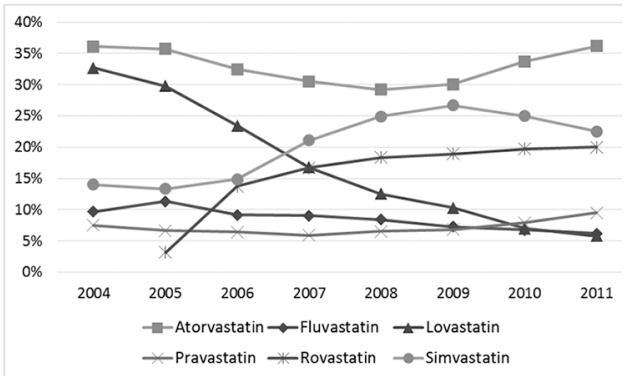

j. Without liver injury history

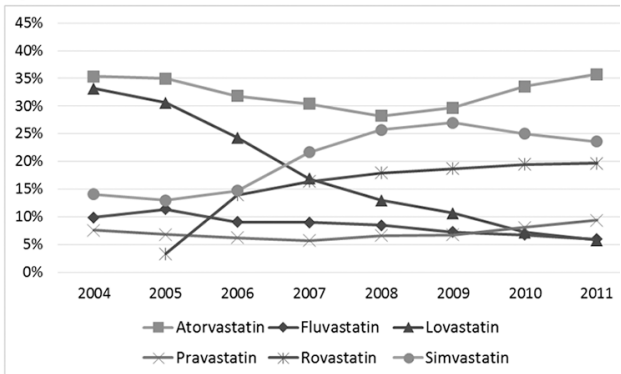

Figure 3 Prescribing rates of statins among new statin users with/without history of specific diseases.

address these gaps. As new PCSK9 inhibitors become available on Taiwan's NHI, our findings provide baseline trends that can be used in a future study to examine how new PCSK9 inhibitors impact the market of cholesterol medications. 


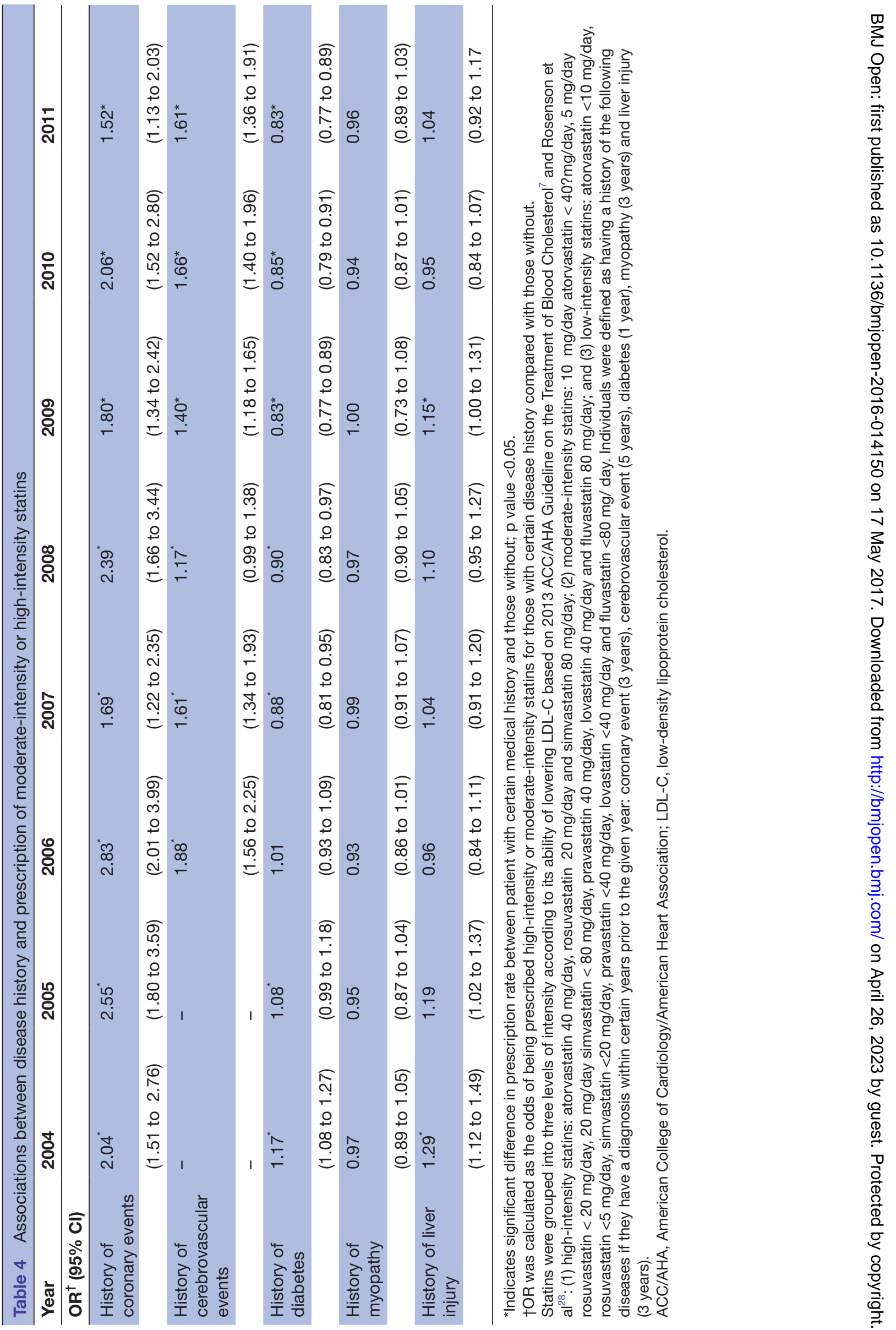




\section{CONCLUSION}

Our study with national cohorts of new statin users in each year during 2002-2011 in Taiwan found that the majority of new users initiated on statin monotherapy, and atorvastatin was the most commonly prescribed statin. While patients with history of CVD were more likely to be prescribed higher intensity statins compared with those without, which is consistent with clinical guidelines, such difference was not found comparing those with and without diabetes. Appropriateness of statin use among diabetes needs further investigation.

Contributor $\mathrm{JCH}$ and $\mathrm{HCH}$ conceptualised and designed the study. $\mathrm{HCH}$ collected data, performed analysis and drafted the manuscript. JCH and CYL reviewed all data and revised the manuscript critically for intellectual content. All authors approved the final version for submission.

Competing interests None declared.

Ethics approval National Cheng Kung University Hospital.

Provenance and peer review Not commissioned; externally peer reviewed.

Data sharing statement The authors have obtained nationwide, monthly claims data for lipid-lowering agents, from 2002 to 2011, from the Taiwan National Health Insurance Research Database (NHIRD). NHIRD does not permit external sharing of any of the data elements. No additional data available.

Open Access This is an Open Access article distributed in accordance with the Creative Commons Attribution Non Commercial (CC BY-NC 4.0) license, which permits others to distribute, remix, adapt, build upon this work non-commercially, and license their derivative works on different terms, provided the original work is properly cited and the use is non-commercial. See: http://creativecommons.org/ licenses/by-nc/4.0/

(C) Article author(s) (or their employer(s) unless otherwise stated in the text of the article) 2017. All rights reserved. No commercial use is permitted unless otherwise expressly granted.

\section{REFERENCES}

1. WHO. Cardiovascular diseases (CVDs). 2015. http://www.who.int/ mediacentre/factsheets/fs317/en/ (accessed 3 Apr, 2015).

2. Statistics of causes of death. Taiwan: Ministry of Health and Welfare, 2015.

3. Castelli WP, Garrison RJ, Wilson PW, et al. Incidence of coronary heart disease and lipoprotein cholesterol levels. the framingham study. JAMA 1986;256:2835-8.

4. Wilson PW, D'Agostino RB, Levy D, et al. Prediction of coronary heart disease using risk factor categories. Circulation 1998;97:1837-47.

5. Sharrett AR, Ballantyne CM, Coady SA, et al. Coronary heart disease prediction from lipoprotein cholesterol levels, triglycerides, lipoprotein(a), apolipoproteins A-I and B, and HDL density subfractions: the atherosclerosis risk in communities (ARIC) Study. Circulation 2001;104:1108-13.

6. Grundy SM, Cleeman JI, Merz CN, et al. Implications of recent clinical trials for the national cholesterol education program adult treatment panel III guidelines. Circulation 2004;110:227-39.

7. Stone NJ, Robinson JG, Lichtenstein AH, et al. ACC/AHA guideline on the treatment of blood cholesterol to reduce atherosclerotic cardiovascular risk in adults: a report of the American college of cardiology/American heart association task force on practice guidelines. Circulation 2013;2014:S1-45.

8. NICE Clinical Guideline 181. Lipid modification: cardiovascular risk assessment and the modification of blood lipids for the primary and secondary prevention of cardiovascular disease. 2014. London: National Clinical Guideline Centre, 2014.

9. Reiner Z, Catapano AL, De Backer G, et al. ESC/EAS guidelines for the management of dyslipidaemias: the task force for the management of dyslipidaemias of the european society of cardiology (ESC) and the european atherosclerosis society (EAS). Eur Heart $J$ 2011;32:1769-818.

10. Baigent C, Keech A, Kearney PM, et al. Efficacy and safety of cholesterol-lowering treatment: prospective meta-analysis of data from 90,056 participants in 14 randomised trials of statins. Lancet 2005;366:1267-78.
11. Fulcher J, O'Connell R, Voysey M, et al. Efficacy and safety of LDL-lowering therapy among men and women: meta-analysis of individual data from 174,000 participants in 27 randomised trials. Lancet 2015;385:1397-405.

12. Maron DJ, Fazio S, Linton MF. Current perspectives on statins. Circulation 2000;101:207-13.

13. Ford I, Murray $\mathrm{H}, \mathrm{McC}$ cowan $\mathrm{C}$, et al. Long-Term safety and efficacy of lowering Low-Density lipoprotein cholesterol with statin therapy: 20-year Follow-Up of west of Scotland coronary prevention study. Circulation 2016;133:1073-80.

14. Pharmaceutical Benefit and Reimbursement Scheme. . National Health Insurance Administration, Ministry of Health and Welfare, Taiwan, 2016.

15. IMS Institute for Healthcare Informatics. Top 20 global therapy areas 2014. England and Wales: IMS Health MIDAS, 2014.

16. IMS institute for healthcare informatics. The global use of medicines: outlook through 2016. USA: IMS Institute for Healthcare Informatics, 2012.

17. Taylor FC, Huffman M, Ebrahim S. Statin therapy for primary prevention of cardiovascular disease. JAMA 2013;310:2451-2.

18. Walley T, Folino-Gallo P, Stephens $\mathrm{P}$, et al. Trends in prescribing and utilization of statins and other lipid lowering drugs across Europe 1997-2003. Br J Clin Pharmacol 2005;60:543-51.

19. DeWilde S, Carey IM, Bremner SA, et al. Evolution of statin prescribing 1994-2001: a case of agism but not of sexism? Heart 2003:89:417-21.

20. Lin M-J. The dyslipidemia drugs use in Taiwan. Taiwan: Kaohsiung Medical University, 2005.

21. Wung D-C. Drug utilization evaluation and therapeutic equivalence of statins. Taiwan: National Cheng Kung University,, 2007.

22. Baigent $\mathrm{C}$, Blackwell L, Emberson J, et al. Efficacy and safety of more intensive lowering of LDL cholesterol: a meta-analysis of data from 170,000 participants in 26 randomised trials. Lancet 2010;376:1670-81.

23. Lepor NE, Kereiakes DJ. The PCSK9 inhibitors: a novel therapeutic target enters clinical practice. Am Health Drug Benefits 2015;8:483-9.

24. Li YC, Huang WL. Effects of adherence to statin therapy on health care outcomes and utilizations in Taiwan: a Population-Based study. Biomed Res Int 2015;2015:149573.

25. National health insurance annual report 2014-2015. 2014http://nhird. nhri.org.tw/en/index.htm (accessed 6 Sep, 2015).

26. National health insurance reseach database. http://nhird.nhri.org.tw/ en/Data_Subsets.html (accessed 6 Sep, 2015).

27. ATC 2011. http://www.whocc.no/atc/structure_and_principles/ (accessed 13 Sep, 2015)

28. Rosenson RS, Kent ST, Brown TM, et al. Underutilization of highintensity statin therapy after hospitalization for coronary heart disease. J Am Coll Cardiol 2015;65:270-7.

29. International classification of diseases ninth revision, clinical modification (ICD-9-CM). (accessed 6 Sep, 2015).

30. Lo Re V, Haynes K, Goldberg D, et al. Validity of diagnostic codes to identify cases of severe acute liver injury in the US Food and Drug Administration's Mini-Sentinel Distributed Database. Pharmacoepidemiol Drug Saf 2013;22:861-72.

31. Kuncova K, Sedlackova M, Vencovsky J, et al. Inflammatory myopathy associated with statins: report of three cases. Mod Rheumatol 2014;24:366-71.

32. Finegold JA, Manisty $\mathrm{CH}$, Goldacre B, et al. What proportion of symptomatic side effects in patients taking statins are genuinely caused by the drug? systematic review of randomized placebocontrolled trials to aid individual patient choice. Eur J Prev Cardiol 2014;21:464-74.

33. Alberton M, Wu P, Druyts E, et al. Adverse events associated with individual statin treatments for cardiovascular disease: an indirect comparison meta-analysis. QJM 2012;105:145-57.

34. Bhardwaj SS, Chalasani N. Lipid-Lowering agents that cause DrugInduced hepatotoxicity. Clin Liver Dis 2007;11:597-613.

35. Gillett RC, Norrell A. Considerations for safe use of statins: liver enzyme abnormalities and muscle toxicity. Am Fam Physician 2011;83:711-6.

36. Cheng CL. Pharmacoepidemiologic Research for Ischemic Stroke in Elderly Patients Who Taking Cyclo-oxygenase-2 inhibitors or Conventional Non-steroidal Anti-inflammatory Drugs (PhD Dissertation). Taiwan: National Cheng Kung University, 2010.

37. J-W W. Prescribing patterns and safety of HMG-CoA reductase inhibitors usage within national health insurance research database: a Drug-Interaction approach. Master Thesis. National Taiwan University, 2005.

38. Chen GL, Hsiao FY, Dong YH, et al. Statins and the risk of liver injury: a population-based case-control study. Pharmacoepidemiol Drug Saf 2014;23:719-25. 
39. Ferrajolo C, Arcoraci V, Sullo MG, et al. Pattern of statin use in southern italian primary care: can prescription databases be used for monitoring long-term adherence to the treatment? PLoS One 2014:9:e102146.

40. Svensson E, Nielsen RB, Hasvold P, et al. Statin prescription patterns, adherence, and attainment of cholesterol treatment goals in routine clinical care: a danish population-based study. Clin Epidemiol 2015;7:213-23.

41. O'Keeffe AG, Nazareth I, Petersen I. Time trends in the prescription of statins for the primary prevention of cardiovascular disease in the United Kingdom: a cohort study using the health improvement network primary care data. Clin Epidemiol 2016;8:123-32.

42. Deambrosis P, Saramin C, Terrazzani G, et al. Evaluation of the prescription and utilization patterns of statins in an Italian local health unit during the period 1994-2003. Eur J Clin Pharmacol 2007;63:197-203.

43. Geleedst-De Vooght M, Maitland-van der Zee AH, Schalekamp T, et al. Statin prescribing in the elderly in the Netherlands: a pharmacy database time trend study. Drugs Aging 2010;27:589-96.

44. Naci $\mathrm{H}$, Brugts JJ, Fleurence R, et al. Comparative benefits of statins in the primary and secondary prevention of major coronary events and all-cause mortality: a network meta-analysis of placebo-controlled and active-comparator trials. Eur J Prev Cardiol 2013;20:641-57.

45. Purvis L. Rx price watch case study: efforts to reduce the impact of generic competition for lipitor: grey literature report. 2013

46. Smith MEB, Lee MEB, Haney MEB, et al. Drug Class Review: HMGCoA Reductase Inhibitors (Statins) and Fixed-dose Combination Products Containing a Statin: Final Report Update 5. Portland (OR:
Oregon Health \& Science University, 2009. https://www.ncbi.nlm.nih. gov/books/NBK47273/21089253.

47 Salami JA, Warraich $\mathrm{H}$, Valero-Elizondo J, et al. National trends in statin use and expenditures in the US adult population from 2002 to 2013: insights from the medical expenditure panel survey. JAMA Cardiol 2017;2:56-65.

48 Cannon CP, Blazing MA, Giugliano RP, et al. Ezetimibe added to statin therapy after acute coronary syndromes. N Engl J Med 2015;372:2387-97.

49 Kastelein JJ, Akdim F, Stroes ES, et al. Simvastatin with or without ezetimibe in familial hypercholesterolemia. N Engl J Med 2008;358:1431-43.

50 Chin-Feng Hsuan T-LL, Chang H-L, Tseng W-K, et al. A retrospective study of statin use and its effectiveness in Taiwanese. Acta Cardiologica Sinica 2009;25:18-25.

51 Third report of the national cholesterol education program (NCEP) Expert panel on detection, evaluation, and treatment of high blood cholesterol in adults (Adult treatment panel III) final report. Circulation 2002;106:3143-421.

52 Macedo AF, Douglas I, Smeeth L, et al. Statins and the risk of type 2 diabetes mellitus: cohort study using the UK clinical practice pesearch datalink. BMC Cardiovasc Disord 2014;14:85.

53 Yoon D, Sheen SS, Lee S, et al. Statins and risk for new-onset diabetes mellitus: a real-world cohort study using a clinical research database. Medicine 2016;95:e5429.

54 Preiss D, Seshasai SR, Welsh P, et al. Risk of incident diabetes with intensive-dose compared with moderate-dose statin therapy: a meta-analysis. JAMA 2011;305:2556-64. 